\title{
Relação entre a flexibilidade do caule de seringueira e a carência de boro ${ }^{(1)}$
}

\author{
Larissa Alexandra Cardoso Moraes ${ }^{(2)}$, Vicente Haroldo de Figueiredo Moraes $^{(2)}$ e Adônis Moreira(3)
}

\begin{abstract}
Resumo - Em algumas culturas com carência de B, observou-se menor deposição de lignina nos elementos do xilema, formando paredes finas e pouco resistentes e menor translocação de carboidratos das folhas para outras partes da planta. Com o objetivo de detectar essas alterações anatômicas no xilema de caules extremamente flexíveis de seringueira (Hevea spp.), que apresentavam sintomas de deficiência de B, realizou-se um estudo anatômico comparativo entre plantas com e sem sintomas de deficiência, quanto à espessura das paredes e grau de deposição de lignina e celulose, bem como quanto à concentração de grãos de amido no parênquima do xilema. Não foi observada variação significativa entre a espessura e o grau de deposição de lignina nas paredes dos elementos do xilema de plantas com e sem sintomas. No entanto, plantas com sintomas apresentaram lamela média de espessura muito reduzida, com menor intensidade de coloração, o que reflete a insuficiência de pectato de cálcio, composto responsável pela adesão entre as células e cuja síntese é bloqueada pela carência de boro. A causa da flexibilidade dos caules foi atribuída à menor coesão entre as células.
\end{abstract}

Termos para indexação: Hevea, lignificação, anatomia vegetal, xilema.

\section{Relationship between stem flexibility of rubber tree and boron deficiency}

\begin{abstract}
In some boron deficient crops, less lignin build up has been observed in xylem elements, which have thinner and weaker walls and also a lower translocation of carbohydrates from leaves to other plant organs. In order to detect these anatomical changes in the xylem of very flexible stem of rubber trees (Hevea spp.) displaying boron deficiency symptoms, a comparative anatomical study was made of the wall thickness, the degree of lignin and cellulose deposition as well as starch grain concentration in the wood parenchyma. No difference was found in thickness and lignin deposition in the walls of xylem elements of normal and boron deficient plants. However, the middle lamella of deficient plants was much thinner, with less intensive staining, reflecting a low supply of calcium pectate, which promotes the adhesion between cells and has its synthesis impaired by boron deficiency. The cause of the flexibility was considered to be due to a lower cohesion between cells.
\end{abstract}

Index terms: Hevea, lignification, plant anatomy, xylem.

\section{Introdução}

Em seringal localizado no Município de Presidente Figueiredo, AM, foram observadas plantas de seringueiras, de aproximadamente três anos de idade, com caule extremamente flexível, em alguns casos com a copa ao nível do solo.

\footnotetext{
(1) Aceito para publicação em 14 de junho de 2002.

(2) Embrapa-Centro de Pesquisa Agroflorestal da Amazônia Ocidental (CPAA), Caixa Postal 319, CEP 69011-970 Manaus, AM. E-mail: larissa@cpaa.embrapa.br, vicente@cpaa.embrapa.br

(3) Embrapa-CPAA. Bolsista do DCR/CNPq. E-mail: adonis@cpaa.embrapa.br
}

Essas plantas tinham como copa enxertada o clone IAN 6543 (Hevea pauciflora $\times$ H. brasiliensis) e como painel, o Fx 3899 (H. brasiliensis $\mathrm{x}$ $H$. benthamiana), apresentando folíolos com sintomas semelhantes aos de deficiência de B, mostrando-se coerente com a análise foliar, em que o B foi o único nutriente cujo teor nos folíolos com sintomas foi mais baixo do que nos folíolos de plantas normais. Tal fato, no entanto, não pode ser considerado como evidência conclusiva de que se trata de carência desse nutriente, pois os níveis críticos de B são mal definidos em relação à seringueira (Pereira et al., 1985).

O papel fisiológico do $\mathrm{B}$ nas plantas ainda não está totalmente entendido, entretanto, sabe-se da sua importância na formação da parede celular, mais es- 
pecificamente na síntese dos seus componentes, como a pectina, a celulose e a lignina. Na ausência de $\mathrm{B}$, ocorre uma redução dessas substâncias na parede das células do lenho, que se tornam mais finas. O B atua via ativação da uridina difosfato (UDP) glucose piranofosforilase, disponibilizando a UDP glicose para síntese da pectina e celulose (Gupta, 1993; Loué, 1993). Por sua vez, esse nutriente atua na síntese de lignina pela formação de complexos de boratos com certos fenóis, regulando a taxa de fenóis livres e aumentando os fenóis, precursores da síntese de lignina (Lewis, 1980; Pilbeam \& Kirkby, 1983; Shkolnik, 1984).

Estudos de partes de plantas deficientes em B mostraram deslignificação das paredes das células do esclerênquima (Marschner, 1995). Em plantas de girassol deficientes em B, observou-se redução sensível no conteúdo total de lignina e da enzima peroxidase, catalisadora da síntese de lignina (Dutta \& McIlrath, 1964). Uma das principais razões do B não ser essencial para fungos é que estes não sintetizam lignina, com exceção daqueles que atacam a madeira (Lewis, 1980).

Muitos autores defendem a hipótese de que, em condições de deficiência de $\mathrm{B}$, ocorre uma redução no transporte da sacarose das folhas para outras partes da planta, pela maior produção de calose, a qual provoca a obstrução do floema, principal via de transporte da sacarose (Venter \& Currier, 1977; Loué, 1993), ou pela redução da síntese de sacarose por inibição da ação de fosforilases ou redução na síntese de uracila, precursor da uridina difosfato glucose, coenzima essencial na formação da sacarose (Loué, 1993; Marschner, 1995). Nesse caso, a menor espessura das paredes seria conseqüência de menor disponibilidade de carboidratos no xilema, já que essas substâncias são a base dos constituintes da parede do xilema.

O objetivo deste trabalho foi verificar, através de um estudo comparativo da anatomia interna de plantas com e sem encurvamento do caule, se a maior flexibilidade do caule seria causada pela redução na espessura e componentes das paredes dos elementos do xilema.

\section{Material e Métodos}

Foram coletadas amostras do caule da copa enxertada (clone IAN 6543), $30 \mathrm{~cm}$ acima da união do enxerto, de uma planta sem sintomas de carência de B nas folhas e de outra planta com sintomas e encurvamento do caule (amos- tras 1 e 4, respectivamente). Do painel Fx 3899 sob a copa enxertada, foram coletadas amostras do caule, $30 \mathrm{~cm}$ abaixo da união do enxerto, de duas plantas sem sintomas e de duas com sintomas (amostras 2 e 3 e amostras 5 e 6, respectivamente). As amostras de $3 \mathrm{~cm}$ de comprimento e $1 \mathrm{~cm}$ de largura foram retiradas com canivete de enxertia, e incluíam a casca e cerca de $0,5 \mathrm{~cm}$ de lenho. Após a coleta foi descartada a camada de casca dura, e manteve-se o restante da casca aderida ao lenho.

As amostras foram fixadas em FAA $(90 \mathrm{~mL}$ de etanol em solução aguosa a 70\%, $5 \mathrm{~mL}$ de ácido acético e $5 \mathrm{~mL}$ de formalina) (Berlyn \& Mikshe, 1976) e posteriormente lavadas por imersão, de cinco a dez minutos, em água destilada, por ocasião do seccionamento em micrótomo de Ranvier, no sentido transversal, com 30 a $50 \mathrm{~mm}$, abrangendo a casca macia e o lenho interno e periférico. Os cortes foram selecionados em número variável de dez a oito para coloração e montagem. Exceto quando especificado, o meio de montagem usado foi a glicerina. Quanto à coloração, os cortes foram enxugados rapidamente em papel absorvente antes da imersão no corante.

Utilizou-se o teste de coloração com solução aquosa de azul de toluidina a $0,05 \%$ e $\mathrm{pH} 6,2$ por cinco minutos, nas paredes lignificadas (coloração verde azulada) e parede primária (coloração púrpura). O estudo da lâmina foi feito em microscópio Zeiss de campo claro com oculares com aumento de 10x e objetiva de 40x, procedendo-se de forma idêntica após cada um dos testes a seguir.

Na determinação da concentração de grãos de amido, os cortes foram montados diretamente em lugol com composição de acordo com Johansen (1940). Quanto à celulose, utilizou-se o teste de cloroideto de zinco, em que os cortes foram tratados por cinco minutos em reagente de composição definida por Berlyn \& Mikshe (1976), e o teste de iodo, em que os cortes foram montados em lugol, depositando-se uma gota de ácido sulfúrico sobre a lâmina, ao lado da lamínula e observando-se ao microscópio a mudança de coloração à medida que o ácido se difundia no meio de montagem. Em relação à lignina, utilizou-se o teste do floroglucinol, em que os cortes foram corados durante dez minutos em reagente de composição definida por Berlyn \& Mikshe (1976).

A mensuração da espessura das paredes dos traqueídeos, do lenho periférico e do lenho interno, foi feita em lâminas coradas em azul de toluidina com objetiva de imersão (100x) com fator de correção de 4,8, e determinada com lâmina micrométrica de subdivisão de $10 \mu \mathrm{m}$. De cada amostra, foram feitas 50 mensurações das paredes duplas de traqueídeos contíguos, dividindo-se o resultado por dois, admitindo-se igualdade de espessura de paredes contíguas. A análise estatística foi feita pelo teste $t$ com dados em- 
parelhados, que compara os contrastes entre as amostras 1 e 4 e entre 5 e 2 e 6 e 2 . Não foram estudados contrastes com as amostras 3 , retiradas de planta com aparência normal, em virtude do menor diâmetro do ramo.

Na observação da estrutura do câmbio e das células jovens do lenho adjacente ao câmbio, o material fixado em FAA, contendo casca e lenho, foi incluído em parafina com a seqüência de desidratação do Butanol terciário descrita por Berlyn \& Mikshe (1976). A seguir, foi seccionado a $30 \mu \mathrm{m}$ em micrótomo rotatório de Jung, com as séries de secções montadas nas lâminas, seguindo-se eliminação da parafina com xilol, reidratação em etanol absoluto, 95\%, $70 \%, 50 \%$ e $35 \%$. A coloração foi feita por três minutos em solução aquosa de azul de toluidina $0,05 \%$, seguida de desidratação na sequiência ascendente de concentração de etanol, passagem por xilol e montagem em resina sintética.

\section{Resultados e Discussão}

Foram encontradas diferenças entre as amostras de lamela média e parede lignificada, quanto à coloração em azul de toluidina, apenas na margem externa correspondente às células adjacentes ao câmbio do lenho periférico, ou seja, células recém-formadas.

Nas amostras correspondentes às plantas normais (amostra 1, clone IAN 6543, e amostras 2 e 3, clone Fx 3899), a cor púrpura da lamela média é mais nítida, a espessura desta é maior, permanecendo em células em processo de lignificação, em comparação com as amostras de plantas com sintomas semelhantes ao de carência de B (amostra 4, clone IAN 6543, e amostras 5 e 6, clone Fx 3899), em que se observa mudança brusca da camada de células não lignificadas (com lamela média extremamente delgada) para as células de parede lignificadas, não sendo mais visível a coloração púrpura da pectina. Além disso, nas amostras de plantas com sintomas, os elementos do lenho mostram, nos cortes, alta freqüência de separação das paredes ou das camadas constituintes da parede (Figura 1a), inclusive dos vasos lenhosos (Figura 1b), enquanto nas plantas sem sintomas o mesmo não ocorreu, e o contorno das paredes é bastante nítido (Figura 1c) em contraste com a aparência difusa das células do lenho das plantas com sintomas.

Nos cortes corados com lugol, observou-se a presença abundante de grãos de amido, tanto no lenho periférico como no interno nas amostras de plantas sem sintomas de deficiência de boro (Figura 2a) dos dois clones IAN 6543 (amostra 1) e Fx 3899 (amostras 2 e 3). Nas amostras 4, 5 e 6 das plantas com sintomas (Figura 2b), foram encontrados poucos grãos de amido.

No teste de cloroideto de zinco em relação a celulose, não foram encontradas diferenças nas lâminas das amostras, e obteve-se coloração positiva azul intensa em todas as amostras nos elementos do lenho. No teste do iodo, seguido de adição de ácido sulfúrico, os resultados foram semelhantes, com melhor caracterização da celulose pela coloração azul no conteúdo interno dos fibrotraqueídeos. Nessas lâminas, observou-se também que, nas áreas dos cortes correspondentes à casca do caule das plantas com sintomas, ocorreu um acúmulo anormal de
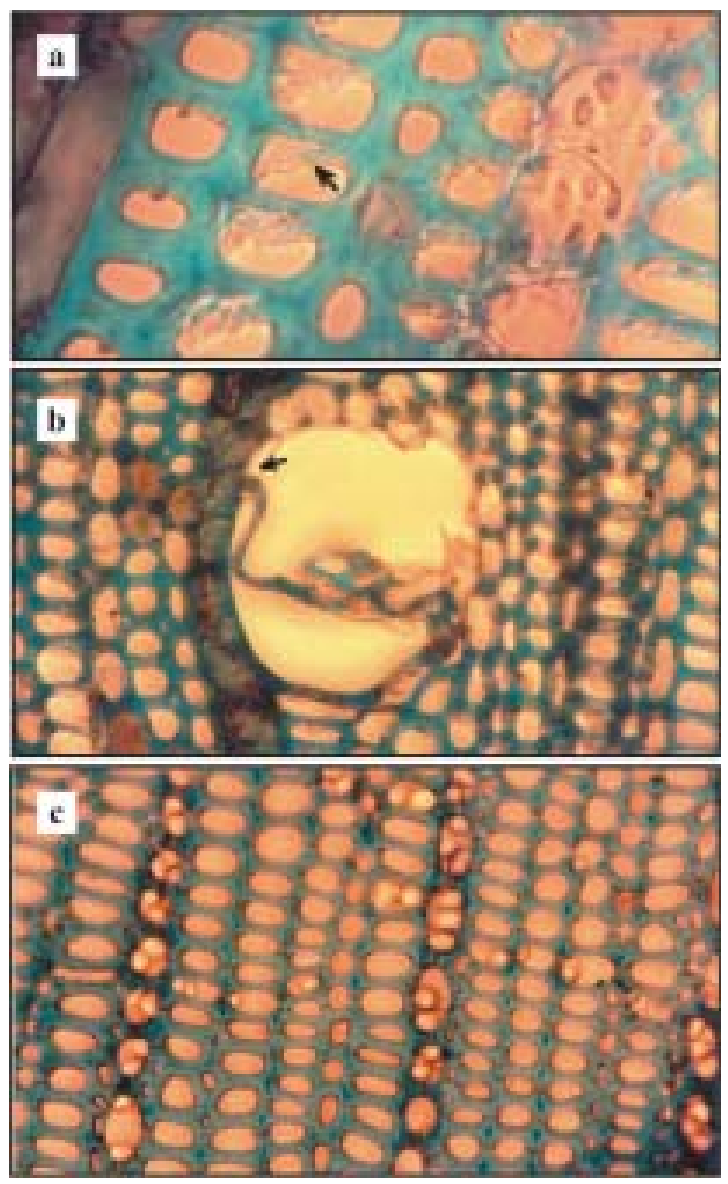

Figura 1. Cortes transversais do lenho de seringueira do clone IAN 6543 corados com azul de toluidina (objetiva 100x, ocular 10x), em plantas com (a e b) e sem (c) sintomas de deficiência de boro, apresentando: a) descolamento das paredes dos elementos do xilema; b) vaso lenhoso com o mesmo descolamento; c) células íntegras com contornos das paredes bem definidos. 
cristais de oxalato de cálcio. Não foram observadas diferenças de intensidade de coloração também no teste do floroglucinol quanto à lignina, em que todas as amostras adquiriram coloração rósea intensa, o que indica não haver diferença no grau de lignificação.

Não houve diferença significativa entre as amostras 1 e 4 , amostras 5 e 2 e amostras 6 e 2 quanto à espessura das paredes dos traqueídeos do lenho periférico e do lenho interno (Tabela 1). As médias de menor espessura da amostra número três, nos dois tipos de lenho, devem ser atribuídas ao menor diâmetro do ramo dessa amostra, razão por que foi excluída da análise estatística.

Os cortes incluídos em parafina confirmaram as observações dos cortes feitos sem inclusão. Os elementos do xilema recém-formados pelo câmbio têm paredes primárias mais finas e produzem reação menos intensa de pectina com azul de toluidina nas

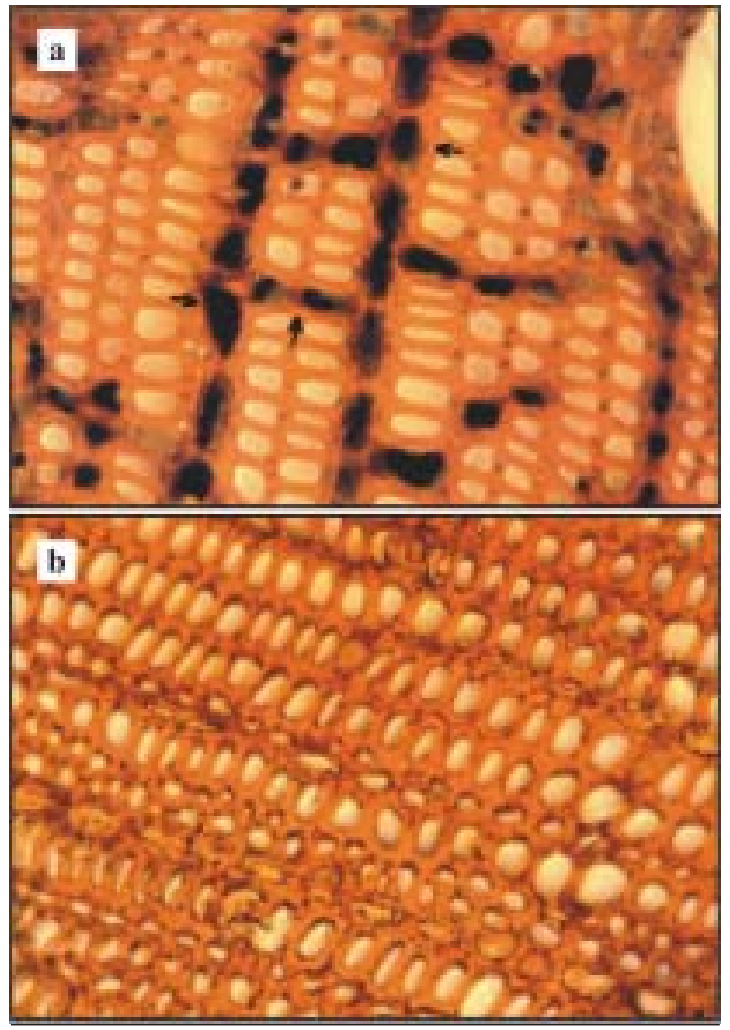

Figura 2. Cortes transversais do lenho de seringueira do clone IAN 6543 corados com lugol (objetiva 40x, ocular 10x) mostrando a presença (a) e a ausência (b) de grãos de amido no parênquima radial e longitudinal de plantas sem (a) e com (b) sintomas foliares de deficiência de boro. amostras de plantas com sintomas (Figura 3a). O esmagamento das células nos cortes indicam falta de rigidez. Nas plantas com aparência normal, a lamela média apresenta paredes primárias espessas e coloração avermelhada típica de lamela média com azul de toluidina e não ocorre esmagamento das células (Figura 3b).

A análise foliar revelou que, em todas as amostras coletadas de plantas que apresentavam folíolos com sintomas semelhantes aos de carência de B (Viégas et al., 2000) e encurvamento do caule, o teor desse nutriente era mais baixo $\left(35 \mathrm{mg} \mathrm{kg}^{-1}\right)$ do que o seu teor nas folhas consideradas normais $\left(75 \mathrm{mg} \mathrm{kg}^{-1}\right)$. Os teores dos demais nutrientes analisados foram próximos nas plantas com e sem sintomas de deficiência: 22,79 $\mathrm{g} \mathrm{kg}^{-1}$ e 23,40 $\mathrm{g} \mathrm{kg}^{-1} \mathrm{de} \mathrm{N}$; $1,43 \mathrm{~g} \mathrm{~kg}^{-1}$ e $1,36 \mathrm{~g} \mathrm{~kg}^{-1}$ de $\mathrm{P} ; 7,43 \mathrm{~g} \mathrm{~kg}^{-1}$ e $8,80 \mathrm{~g} \mathrm{~kg}^{-1}$ de $\mathrm{K} ; 7,62 \mathrm{~g} \mathrm{~kg}^{-1}$ e 7,73 $\mathrm{g} \mathrm{kg}^{-1}$ de Ca; $2,64 \mathrm{~g} \mathrm{~kg}^{-1} \mathrm{e}$ $2,46 \mathrm{~g} \mathrm{~kg}^{-1}$ de $\mathrm{Mg} ; 15 \mathrm{mg} \mathrm{kg}^{-1}$ e $15 \mathrm{mg} \mathrm{kg}^{-1} \mathrm{de} \mathrm{Cu}$; $173 \mathrm{mg} \mathrm{kg}^{-1}$ e $153 \mathrm{mg} \mathrm{kg}^{-1}$ de Fe; $207 \mathrm{mg} \mathrm{kg}^{-1} \mathrm{e}$ $172 \mathrm{mg} \mathrm{kg}^{-1}$ de Mn e $55 \mathrm{mg} \mathrm{kg}^{-1}$ e $39 \mathrm{mg} \mathrm{kg}^{-1}$ de Zn, respectivamente (Shorrocks, 1964; Haag \& Viégas, 2000).

A hipótese de que o encurvamento do caule ocorreu por causa da formação de elementos do xilema com paredes mais finas não foi confirmada, uma vez que não se observou diferenças de espessura de parede dos traqueídeos e do grau de lignificação das paredes dos elementos do xilema ou no conteúdo de celulose, entre as amostras testadas.

Observou-se ausência de grãos de amido no parênquima do lenho das plantas com sintomas, o que significa que não houve excesso de carboidratos para armazenamento, mas houve suficiência para a síntese dos constituintes da parede secundária. Segundo Tagawa \& Bonner (1957), o pectato de cálcio é o principal responsável pela adesão entre as célu-

Tabela 1. Espessura das paredes dos traqueídeos no lenho periférico e no lenho interno de clones de seringueira ${ }^{(1)}$.

\begin{tabular}{|c|c|c|c|c|}
\hline \multirow[t]{2}{*}{ Clone } & \multicolumn{2}{|c|}{ Lenho periférico $(\mu \mathrm{m})$} & \multicolumn{2}{|c|}{ Lenho interno $(\mu \mathrm{m})$} \\
\hline & $\begin{array}{c}\text { Com } \\
\text { sintomas }\end{array}$ & $\begin{array}{c}\text { Sem } \\
\text { sintomas }\end{array}$ & $\begin{array}{c}\text { Com } \\
\text { sintomas }\end{array}$ & $\begin{array}{c}\text { Sem } \\
\text { sintomas }\end{array}$ \\
\hline IAN 6543 & $11,71(1)$ & $9,48(4)^{\mathrm{ns}}$ & $10,34(1)$ & $10,32(4)^{\mathrm{ns}}$ \\
\hline Fx 3899 & $12,60(2)$ & $10,37(5)^{\mathrm{ns}}$ & $8,21(2)$ & $8,09(5)^{\mathrm{ns}}$ \\
\hline Fx 3899 & $12,60(2)$ & $12,55(6)^{\mathrm{ns}}$ & $8,21(2)$ & $8,45(6)^{\mathrm{ns}}$ \\
\hline
\end{tabular}

(1)Médias de 50 mensurações feitas em cinco cortes para cada amostra;

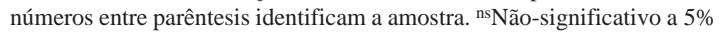
de probabilidade, pelo teste $t$. 
las, sendo esta substância um dos constituintes da lamela média. Nas plantas com encurvamento, constatou-se uma redução na lamela média das células do lenho adjacentes ao câmbio, bem como o acúmulo de cristais de oxalato de cálcio nas cascas do caule dessas plantas. Essas observações são coerentes com a hipótese de Ginzburg (1961) e Loomis \& Durst (1992), que sugerem ser o B um estabilizador dos compostos de $\mathrm{Ca}$ com pectinas. A menor utilização do Ca por causa da carência de B levaria a um excesso desse elemento, imobilizado como oxalato de cálcio, e a uma redução no conteúdo de pectato de cálcio da lamela média, o que causaria uma menor coesão entre as células do lenho das plantas com sintomas. O deslocamento das paredes das células do le-
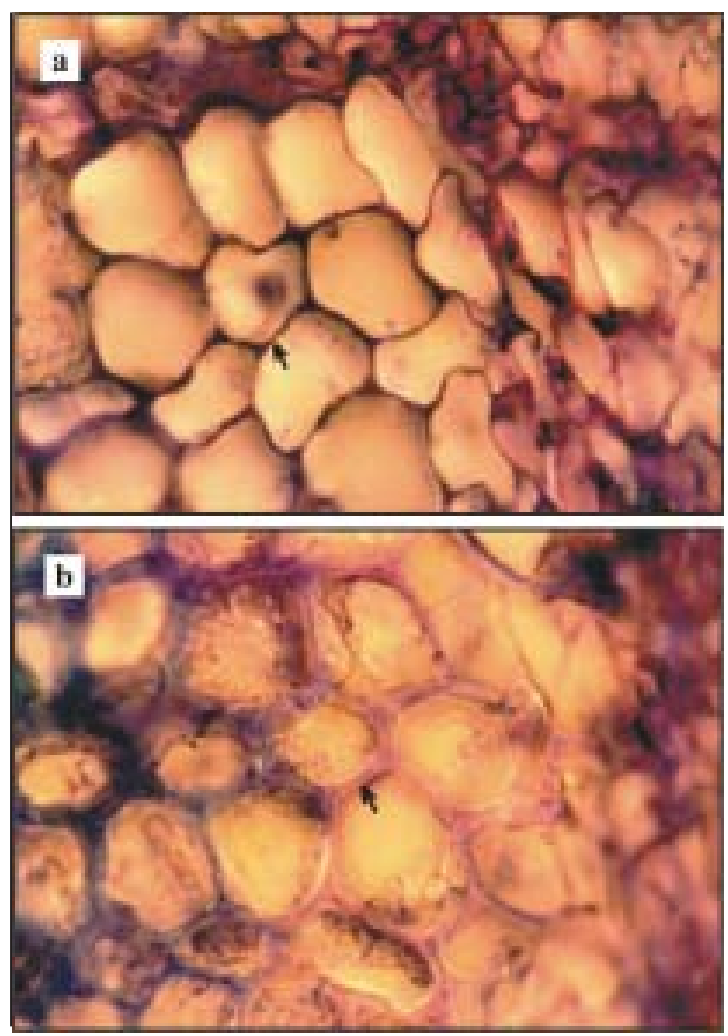

Figura 3. Cortes do lenho de seringueira do clone IAN 6543 corados com azul de toluidina, mostrando elementos do xilema recém-formados pelo câmbio (objetiva 100x, ocular 10x) com paredes primárias delgadas e coloração púrpura quase imperceptível da lamela média (a) e paredes primárias espessas e coloração avermelhada típica de lamela média com azul de toluidina (b) em plantas com (a) e sem (b) sintomas foliares de deficiência de boro. nho, nas plantas com encurvamento do caule, sugeriu essa menor coesão entre as células.

Bolle-Jones (1956) e Shorrocks (1964), na determinação dos sintomas de carência de B em seringueira, induziram a deficiência de B em solução nutritiva, contendo todos os elementos, exceto o B. As plantas foram descartadas logo após o aparecimento e agravamento dos sintomas de deficiência de B que aparecem primeiramente na parte superior da copa, apresentando folhas retorcidas, reduzidas, coriáceas e sem perda de cor. Nessas condições, é provável que o efeito da carência desse nutriente na anatomia do caule tenha passado despercebido.

A carência de B foi registrada por Berniz (1980) em plantas de seringueira com três a quatro lançamentos e cerca de seis anos de idade, não se observando o encurvamento do caule. Essas plantas eram de jardim clonal, sofrendo decapitações periódicas antes de atingirem $2 \mathrm{~m}$ de altura, o que pode explicar a ausência de encurvamento.

Por outro lado, os sintomas da carência de B em seringueira são muito semelhantes aos causados por ataque de trips (Beeley, 1935) ou de ácaros (Shorrocks, 1964), o que também pode explicar a ausência de encurvamento em plantas com esses sintomas nos folíolos.

No presente trabalho, o peso das copas enxertadas foi condição necessária, mas não suficiente, para o encurvamento do caule, já que nas plantas com a mesma copa enxertada, sem sintomas de carência de $B$, não houve encurvamento.

\section{Conclusão}

O encurvamento do caule em seringueira é consequiência da menor coesão entre os elementos do lenho, causada pela redução dos constituintes da lamela média, principalmente do pectato de cálcio, cuja sintese é bloqueada pela carência de boro.

\section{Referências}

BEELEY, F. Hevea thrips. Journal of the Rubber Research Institute of Malaysia, Kuala Lumpur, v. 6, n. 1, p. 58-61, 1935.

BERLYN, G. P.; MIKSHE, J. P. Botanical microtechnique and citochemistry. Ames: Iowa State University Press, 1976. 325 p. 
BERNIZ, J. M. J. Deficiência de zinco, boro e cobre em seringueira. Manaus: Embrapa- CNPSD, 1980. 21 p. (Circular Técnica, 1).

BOLLE-JONES, E. W. Visual symptoms of mineral deficiencies of Hevea brasiliensis. Journal of the Rubber Research Institute of Malaysia, Kuala Lumpur, v. 14, n. 4, p. 493-512, 1956.

DUTTA, T. R.; McILRATH, J. Effects of boron on growth and lignification in sunflower tissue and organ cultures. Botanical Gazette, Chicago, v. 125, p. 89-96, 1964.

GINZBURG, B. Z. Evidence for a protein gel structure crosslinked by metal cations in the intercellular cement of plant tissue. Journal of Experimental Botany, Oxford, v. 12, p. 85-107, 1961.

GUPTA, U. C. Boron and its role in crop production. Boca Raton: CRC Press, 1993. 237 p.

HAAG, H. P.; VIÉGAS, I. J. M. Crescimento e extração de nutrientes da seringueira. In: VIÉGAS, I. J. M.; CARVALHO, J. G. (Ed.). Seringueira: nutrição e adubação no Brasil. Brasília: Embrapa-SCT, 2000. p. 77-121.

JOHANSEN, D. A. Plant microtechnique. New York: McGraw-Hill Book, 1940. 423 p.

LEWIS, O. H. Boron, lignification and the origin of vascular plants: a unified hypothesis. New Phytologist, Cambridge, Inglaterra, v. 84, p. 209-229, 1980.

LOOMIS, W. D.; DURST, R. W. Chemistry and biology of boron. Biofactors, Amsterdam, v. 3, p. 229-239, 1992

LOUÉ, A. Oligo-éléments en agriculture. Antibes: Nathan, 1993. 557 p.
MARSCHNER, H. Mineral nutrition of higher plants. London: Academic, 1995. 889 p.

PEREIRA, E. B. C.; PEREIRA, A. V.; MORAES, V. H. F.; CONCEIÇÃO, H. E. O.; ARNDT, E. Composição mineral de folhas de seis clones de seringueira. Manaus: Embrapa-CNPSD, 1985. 12 p. (Pesquisa em Andamento, 29).

PILBEAM, D. J.; KIRKBY, E. A. The physiological role of boron in plants. Journal of Plant Nutrition, New York, v. 6, p. 563-582, 1983.

SHKOLNIK, M. Y. Trace elements in plants. Amsterdam: Elsevier, 1984. 463 p.

SHORROCKS, U. M. Mineral deficiencies of Hevea brasiliensis and associated cover crops. Kuala Lumpur: Rubber Research Institute of Malaysia, 1964. 76 p.

TAGAWA, T.; BONNER, J. The walls: structure and function. Plant Physiology, Rockville, v. 32, n. 1, p. 207-215, 1957.

VENTER, H. A.; CURRIER, H. B. The effect of boron deficiency on callose formation and ${ }^{14} \mathrm{C}$ translocation in bean (Phaseolus vulgaris L.) and cotton (Gossypium hirsutum L.). American Journal of Botany, Columbus, v. 64, p. 861-865, 1997.

VIÉGAS, I. J. M.; CARVALHO, J. G.; FRAZÃO, D. A. C. Desordens nutricionais na cultura da seringueira: critérios de diagnose para solo e plantas e correção de deficiência. In: VIÉGAS, I. J. M.; CARVALHO, J. G. (Ed.). Seringueira: nutrição e adubação no Brasil. Brasília: Embrapa-SCT, 2000. p. 123-173. 